\title{
Population dynamics of the green mussel Perna viridis from the high spat-fall coastal water of Malacca, Peninsular Malaysia
}

\begin{abstract}
Population parameters such as asymptotic length $(\mathrm{L} \infty)$, growth coefficient $(\mathrm{K})$, mortality rates (Z, F and M), exploitation level (E) and recruitment pattern of green mussel Perna viridis were estimated using length-frequency data from the coast of Malacca, Peninsular Malaysia. Asymptotic length (Lo) was $102.38 \mathrm{~mm}$ and growth coefficient $(\mathrm{K})$ was estimated at 1.50 year -1 . Total mortality $(Z)$ for $P$. viridis was 2.48 year-1, while natural mortality $(M)$ and fishing mortality $(\mathrm{F})$ were 1.69 and 0.79 year-1, respectively. The growth performance index was $(\varphi$ ') 4.197 and the exponent " $b$ " of the length-weight relationship was $2.602( \pm 0.02)$ during the study period. The asymptotic wet weight estimated from length-weight relationship was $40.81 \mathrm{~g}$. Exploitation level (E) of P. viridis was 0.32 while the maximum allowable limit of exploitation (Emax) was 0.43. The recruitment pattern was continuous with one major peak in the months of July-August. The exploitation level (0.32) and lower fishing mortality $(0.79$ year-1) indicate that the green mussel is under-exploited from Malacca coastal waters.
\end{abstract}

Keyword: Population dynamics, Perna viridis, Malacca, Malaysia 